\title{
HANDLINE DALAM PENANGANAN PASCABENCANA ALAM BAGI KELOMPOK NELAYAN DI KAMPUNG LEBO KECAMATAN MANGANITU KABUPATEN KEPULAUAN SANGIHE HANDLINE DALAM PENANGANAN PASCABENCANA ALAM BAGI KELOMPOK NELAYAN DI KAMPUNG LEBO KECAMATAN MANGANITU KABUPATEN KEPULAUAN SANGIHE
}

\author{
Eunike Irene Kumaseh $^{1)}$, Costantein Imanuel Sarapil ${ }^{1)}$, Ganjar Ndaru Ikhtiagung ${ }^{2}$, \\ Erlin Puspaputri ${ }^{3}$ ) \\ ${ }^{1}$ Program Studi Teknologi Penangkapan Ikan, Politeknik Negeri Nusa Utara \\ Jl. Kesehatan No. 1 Kelurahan Sawang Bendar, Tahuna, 95812 \\ ${ }^{2}$ Politeknik Negeri Cilacap Jl. Dr. Sutomo No. 1 Sidakaya, Cilacap 537992, Indonesia \\ ${ }^{3}$ Direktorat Kelembagaan, Ditjen Dikti, Kementerian Pendidikan dan Kebudayaan, \\ Gedung Dikti, Pintu Satu Senayan, Jl. Jenderal Sudirman, Jakarta 10270 \\ Email: eunikeirene89@gmail.com
}

\begin{abstract}
Abstrak: Secara administratif, Kampung Lebo merupakan wilayah Kecamatan Manganitu Kabupaten Kepulauan Sangihe Provinsi Sulawesi Utara, dengan luas wilayah sebesar 6,59 km². Jumlah penduduk 1.317 jiwa yaitu $489 \mathrm{KK}$, yang terdiri atas Laki - laki 809 jiwa dan perempuan 508 jiwa. Pada Tanggal 3 Januari 2020, Kampung Lebo dan beberapa kampung di sekitarnya mengalami bencana alam banjir bandang, yang memakan korban jiwa sebanyak 3 orang. Bantuan penyediaan handline dapat membantu nelayan di Kampung Lebo untuk memperbaiki penghidupan mereka yang lebih baik. Handline atau Pancing ulur terdiri atas beberapa komponen yaitu gulungan tali, tali pancing, mata pancing, dan umpan buatan. Solusi yang dilakukan yaitu pemberian alat tangkap Handline bagi nelayan yang mengalami musibah dan pemberian pengetahuan bagi nelayan tentang manajemen keuangan hasil penjualan ikan. Metode pengabdian yaitu memberikan penyuluhan dan pelatihan, pendampingan, dan monitoring serta evaluasi. PKMS Handline memberdayakan kelompok nelayan di Kampung Lebo dalam usaha penangkapan ikan dengan menggunakan alat tangkap handline, bagi masyarakat lokal disebut Bawaede. Hasil tangkapan ada yang dijual dan ada juga yang digunakan untuk kebutuhan konsumsi sehari - hari. Nelayan dapat lebih efektif menangkap ikan dan membantu meningkatkan kehidupan ekonomi masyarakat pesisir.
\end{abstract}

Kata kunci: handline; nelayan; kampung lebo; kabupaten kepulauan sangihe

\begin{abstract}
Abtract: Administratively, Lebo Village is an area of Manganitu District, Regency of Sangihe islands, Province of North Sulawesi, with an area of 6,59 $\mathrm{km}^{2}$. Total population is 1.317 people 489 households, consisting of 809 men and 508 women. On January $3^{\text {rd }}$, 2020, Lebo Village and surrounding villages experienced a flood, which killed 3 people. Handline assistance can help fisher in Lebo Village to improve their livelihoods. Handline consists of several components, namely roller, fishing line, hook, and artificial bait. The solution taken is providing Handline for fisher who experienced disaster and providing knowledge for fisher about financial management of fish sales. The method is providing counseling, training, mentoring, monitoring and evaluation. PKMS Handline empowers groups of fisher in Lebo Village to catch fish using handline, for the local community it is called Bawaede. The catch is sold and used for daily consumption needs. So the handline assistance can help improve the economic life of local community and the fishing ability of the fisher group.
\end{abstract}

Keyword: handline; fisher; lebo village; regency of sangihe islands 


\section{PENDAHULUAN}

Nelayan merupakan salah satu mata pencaharian yang penting karena potensi sumberdaya laut yang melimpah, serta jumlah nelayan mengalami fluktuasi setiap tahun karena adanya nelayan yang kadang berpindah profesi menjadi petani (Kristiawan, Boesono, \& F, 2013). Peningkatan usaha perikanan tangkap dapat dilakukan melalui peningkatan operasi penangkapan, pencarian fishing ground, serta introduksi teknologi penangkapan (Pratama, Gumilar, \& Maulana, 2012).

Secara administratif, Kampung Lebo merupakan wilayah Kecamatan Manganitu Kabupaten Kepulauan Sangihe Provinsi Sulawesi Utara, dengan luas wilayah sebesar $6,59 \mathrm{~km}^{2}$. Jumlah penduduk 1.317 jiwa yaitu 489 KK, yang terdiri atas Laki - laki 809 jiwa dan perempuan 508 jiwa. Sarana pendidikan di wilayah ini mempunyai 2 sekolah tingkat dasar.

Tabel 1. Jumlah Penduduk berdasarkan Pekerjaan.

\begin{tabular}{|c|l|c|c|}
\hline No. & Jenis Pekerjaan & $\begin{array}{c}\text { Jumlah } \\
(\text { orang) }\end{array}$ & $\begin{array}{c}\text { Persentase } \\
(\%)\end{array}$ \\
\hline 1 & Petani & 196 & 44,65 \\
\hline 2 & Nelayan & 51 & 11,62 \\
\hline 3 & Pedagang & 25 & 5,69 \\
\hline 4 & PNS & 34 & 7,74 \\
\hline 5 & Pegawai Swasta & 19 & 4,33 \\
\hline 6 & TNI/ POLRI & 11 & 2,51 \\
\hline 7 & Lainnya & 103 & 23,46 \\
\hline & Total & 439 & 100,00 \\
\hline
\end{tabular}

*Sumber: BPS Kabupaten Kepulauan Sangihe, 2019.

Berdasarkan pada Tabel 1, dapat dilihat bahwa sebagian besar masyarakat Kampung Lebo bekerja sebagai petani. Tetapi, ada sekitar 11,62 persen dimana masyarakat menggantungkan hidupnya melalui pekerjaan sebagai nelayan. Kampung Lebo terletak di wilayah pesisir pantai, sehingga selain bertani, pekerjaan utama dan sampingan untuk sebagian masyarakat adalah melaut. Kondisi pesisir pantai di Kampung Lebo ditunjukkan pada Gambar 1. Pada umumnya, nelayan yang ada di Kampung Lebo menggunakan hand line.

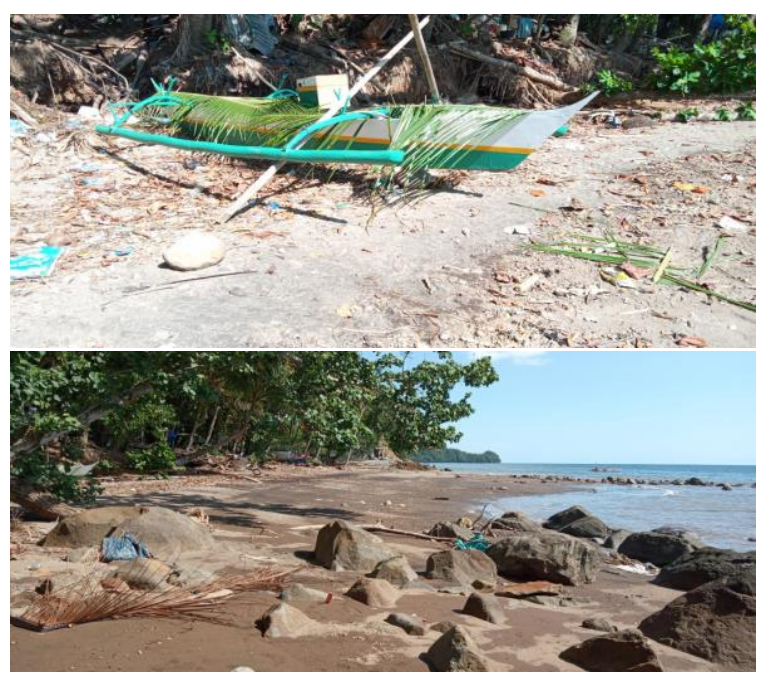

Gambar 1. Kondisi Pesisir Kampung Lebo.

Pada Tanggal 3 Januari 2020, Kampung Lebo dan beberapa kampung di sekitarnya mengalami bencana alam banjir bandang, yang memakan korban jiwa sebanyak 3 orang. Banyak rumah masyarakat yang hancur karena banjir bandang tersebut. Termasuk para nelayan yang merasakan dampaknya, dimana kehilangan alat - alat tangkap yang biasa mereka gunakan untuk mencari nafkah. Kegiatan pengabdian ini bertujuan untuk membantu para nelayan yang ada di Kampung Lebo, khususnya yang menggunakan alat tangkap handline agar bisa melaut kembali. Kebanyakan nelayan menggunakan alat tangkap ini. Pancing ulur (handlines) dikenalkan pertama kali oleh nelayan Bugis di Sendang Biru, Malang (Hargiyatno, Anggawangsa, \& Wudianto, 2013). Sebagian besar nelayan di Kampung Lebo banyak menggunakan alat tangkap pancing ulur (handline).

Handline atau Pancing ulur terdiri atas beberapa komponen yaitu gulungan tali, tali pancing, mata pancing, dan pemberat (Subani, 1989 dalam Rahmat, 2008). Alat tangkap pancing merupakan alat tangkap yang sering digunakan oleh masyarakat pesisir (Manoppo, 2014). Bantuan penyediaan handline dapat membantu nelayan di Kampung Lebo untuk memperbaiki penghidupan mereka yang lebih baik. Program PKMS ini memberikan edukasi tentang alat tangkap handline atau pancing ulur, serta motivasi bagi 
kelompok nelayan yang ada di Kampung Lebo dalam memanfaatkan sumber daya perikanan yang ada, serta meningkatkan pendapatan nelayan.

\section{METODE PELAKSANAAN}

Metode pelaksanaan pengabdian kepada masyarakat di Kampung Lebo yaitu sebagai berikut.

1. Survei

Survei dilakukan dengan tujuan untuk mengetahui secara langsung kondisi sosial ekonomi masyarakat yang ada di lokasi pelaksanaan pengabdian. Tim Pengabdi Politeknik Negeri Nusa Utara melakukan survei di Kampung Lebo untuk melihat kondisi nelayan yang ada di sana.

2. Penyuluhan \& Pelatihan Pembuatan Alat Tangkap Pengembangan metode dan teknologi merupakan salah satu faktor yang mendukung keberhasilan proses penangkapan ikan pada alat tangkap pancing ulur (Adityarini, Asriyanto \& Pramonowibowo, 2012). Kegiatan penyuluhan dilakukan dalam bentuk ceramah tentang pembuatan alat tangkap Handline. Menurut Surahman \& Ilhamdi (2018), Satu unit pancing ulur terdiri atas tali utama, tali cabang, mata pancing dan pemberat. Menurut Manoppo (2014), pancing ulur dioperasikan secara vertikal, diulur pada kedalaman tertentu, dengan mata pancing dikaitkan pada pemberat.

3. Pemberian pengetahuan kepada masyarakat tentang manajemen keuangan dan menumbuhkan jiwa kewirausahaan.

Pelatihan dilakukan bersama - sama dengan kelompok mitra. Manajemen artinya sebagai pengelolaan, pengendalian, atau penanganan secara terampil untuk menangani sesuatu (Herujitmo, 2006 dalam Sarapil \& Wuaten, 2017). Menurut Fahmi (2013) dalam Sadiyah, Nurita, \& Lesmana (2019), manajemen keuangan merupakan gabungan dari ilmu dan seni yang membahas, mengkaji dan menganalisis tentang penggunaan sumberdaya untuk mencari dana, mengelola dan membagi dana dengan tujuan memberikan profit atau kemakmuran dan keberlanjutan bagi usaha. Pemberian pengetahuan tentang manajemen keuangan hasil bagi nelayan bermaksud agar nelayan dapat menata hasil penjualan ikan dengan lebih baik.

4. Pendampingan kepada Masyarakat Pendampingan dilakukan dalam pembuatan alat tangkap handline dan tata kelola keuangan.

5. Monitoring dan Evaluasi

Rancangan monitoring evaluasi digunakan untuk menilai kegiatan pengabdian pada masyarakat telah mencapai tujuan atau tidak. Hariyanti, Werdiningsih, \& Surendro (2011) menyatakan bahwa monitoring dan evaluasi mutlak dilakukan secara terus - menerus untuk memastikan bahwa proses yang dijalankan dapat mencapai tujuan yang ditetapkan. Monitoring dan evaluasi diperlukan untuk menilai kegiatan pelaksanaan telah berjalan dengan baik atau tidak, serta dampaknya bagi kehidupan nelayan (Sarapil \& Kumaseh, 2019).

\section{HASIL DAN PEMBAHASAN}

Program pemberdayaan masyarakat merupakan salah satu program Pemerintah dalam mengentaskan kemiskinan masyarakat pesisir (Sipahelut, dkk, 2010). Program Kemitraan masyarakat stimulus yang dilaksanakan oleh Tim Pengabdi Politeknik Negeri Nusa Utara di Kampung Lebo, bertujuan untuk memberdayakan kelompok nelayan yang ada khususnya pengguna alat tangkap pancing ulur (Handline), agar dapat lebih efektif dalam usaha penangkapan ikan. Kelompok nelayan di Kampung Lebo merupakan nelayan yang aktif menangkap ikan sehari - hari. Handline yang dibuat merupakan handline yang digunakan untuk menangkap ikan demersal dan pelagis khususnya ikan Selar. Kegiatan Pengabdian dilakukan pada hari Jumat, 14 Agustus 2020 di Kantor Kampung Lebo, dengan mengikuti protokol kesehatan, yaitu menjaga jarak, menggunakan masker, dan membatasi jumlah nelayan yang hadir. Nelayan yang hadir merupakan perwakilan dari seluruh 
anggota kelompok nelayan yang ada di Kampung Lebo.
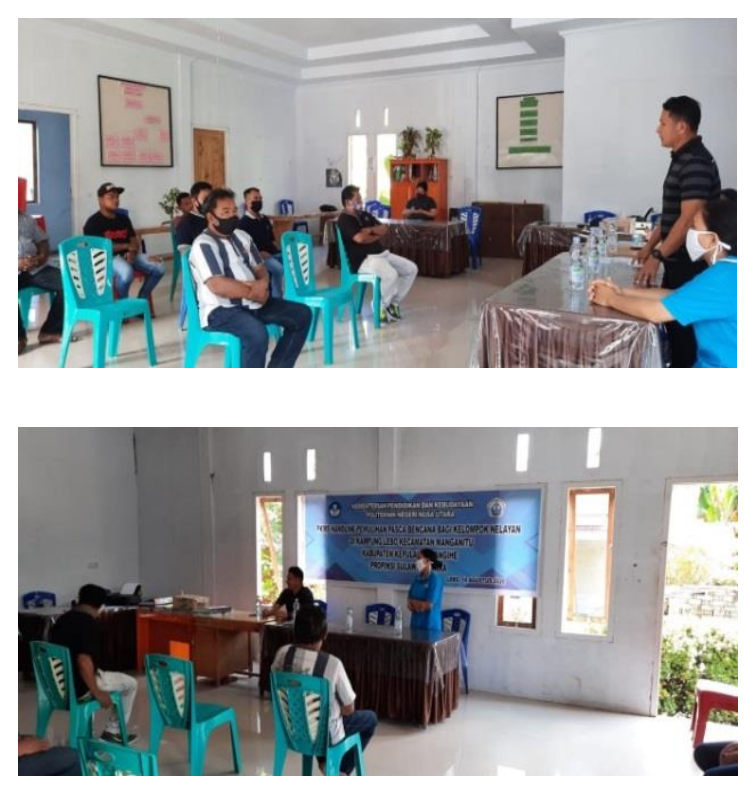

Gambar 2. Pelaksanaan Kegiatan

Tim Pengabdi Politeknik Negeri Nusa Utara memberikan materi singkat dan perkenalan. Kemudian, kegiatan PKMS dilanjutkan dengan pembuatan alat tangkap Handline oleh masing - masing nelayan. Bagi masyarakat lokal, handline yang dibuat dalam kegiatan PKMS ini biasa disebut dengan "Bawaede". Alat tangkap Bawaede ditunjukkan pada Gambar 3 berikut ini.

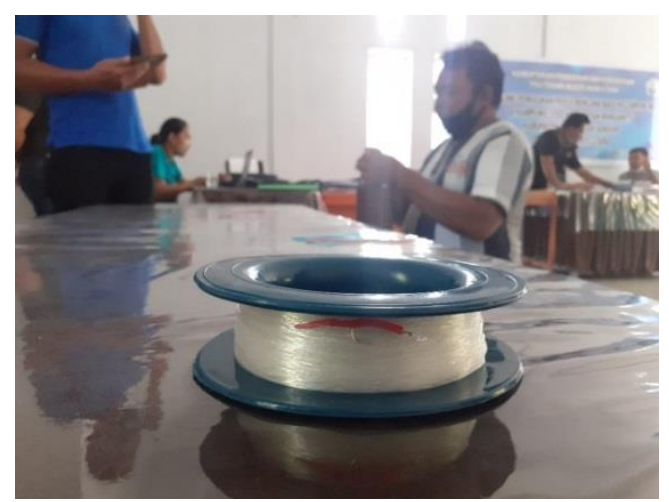

Gambar 3. Alat tangkap Bawaede yang dibuat nelayan.

Pendampingan dilakukan oleh Tim Pengabdi bagi kelompok nelayan dalam pembuatan alat tangkap Handline. Spesifikasi alat tangkap handline "bawaede" ditunjukkan pada Tabel 4 berikut ini
Tabel 2. Spesifikasi 1 unit alat tangkap Handline.

\begin{tabular}{|c|c|c|c|c|}
\hline No. & Uraian & Bahan & Ukuran & Jumlah \\
\hline 1 & $\begin{array}{l}\text { Penggulung } \\
\text { tali }\end{array}$ & Plastik & 03 & 30 \\
\hline \multirow[t]{2}{*}{2} & \multirow[t]{2}{*}{ Tali utama } & \multirow[t]{2}{*}{ Monofilament } & No. 15 & 32 \\
\hline & & & No. 8 & 32 \\
\hline \multirow[t]{2}{*}{3} & \multirow[t]{2}{*}{ Tali cabang } & \multirow[t]{2}{*}{ Monofilament } & No. 10 & 32 \\
\hline & & & No. 6 & 32 \\
\hline \multirow[t]{2}{*}{4} & \multirow{2}{*}{$\begin{array}{l}\text { Umpan } \\
\text { buatan }\end{array}$} & Tiras & - & 120 \\
\hline & & Karet & - & 50 \\
\hline \multirow[t]{4}{*}{5} & \multirow[t]{4}{*}{ Mata kail } & \multirow[t]{4}{*}{ Aluminium } & No. 17 & 32 \\
\hline & & & No. 16 & 16 \\
\hline & & & No. 8 & 16 \\
\hline & & & No. 5 & 16 \\
\hline
\end{tabular}

Pemerintah Kampung Lebo sangat mendukung kegiatan pengabdian kepada masyarakat oleh Tim Pengabdi Politeknik Negeri Nusa Utara. Kelompok nelayan yang ikut juga sangat antusias dalam mengikuti pembuatan alat tangkap Handline. Tim Pengabdi bersama kelompok nelayan dan Pemerintah Kampung yang ada, ditunjukkan pada Gambar 4. Dengan dukungan semua pihak, kegiatan PKMS ini boleh berjalan dengan baik.

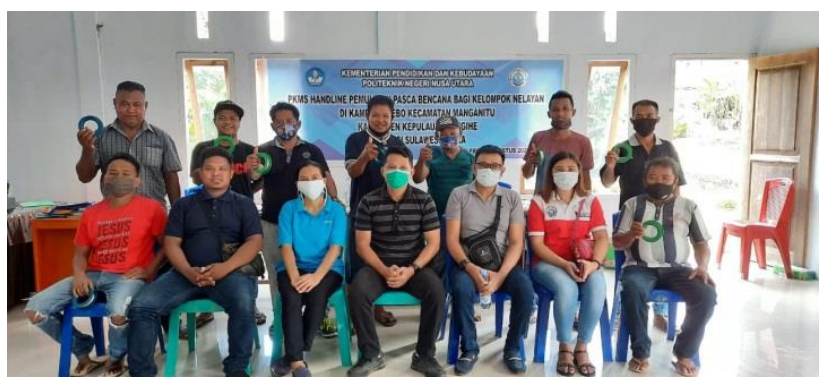

Gambar 4. Tim Pengabdi dan Kelompok Nelayan Kampung Lebo

Kegiatan Monitoring dan evaluasi dilakukan untuk mengawasi pelaksanaan kegiatan pengabdian kepada masyarakat berjalan dengan baik atau tidak (Sarapil \& Kumaseh, 2019). Tim Pengabdi Politeknik Negeri Nusa Utara melakukan monitoring dan evaluasi bagi penggunaan alat tangkap handline yang digunakan oleh kelompok nelayan di Kampung Lebo. Alat tangkap yang diperoleh langsung digunakan untuk menangkap ikan. Hasil tangkapan ada yang dijual, ada juga yang digunakan untuk keperluan makanan seharihari. Sehingga, kegiatan PKMS ini meningkatkan kesejahteraan nelayan di Kampung Lebo. 


\section{KESIMPULAN}

PKMS Handline memberdayakan kelompok nelayan di Kampung Lebo dalam usaha penangkapan ikan dengan menggunakan alat tangkap pancing ulur (handline), bagi masyarakat lokal disebut Bawaede. Kegiatan ini merupakan inisiatif Tim Pengabdi bagi nelayan di Kampung Lebo, setelah peristiwa bencana alam pada bulan Januari lalu. Hasil tangkapan nelayan, ada yang dijual dan ada juga yang digunakan untuk kebutuhan konsumsi keluarga sehari - hari. Nelayan dapat lebih efektif menangkap ikan dan membantu meningkatkan kehidupan ekonomi masyarakat pesisir.

\section{DAFTAR RUJUKAN}

Adityarini, S., Asriyanto, \& Pramonowibowo. 2012. Pengaruh Penggunaan Perbedaan Konstruksi Mata Pancing dan Jenis Umpan pada Pancing Ulur Terhadap Hasil Tangkapan di Kawasan Zona Pemanfaatan Perikanan Tradisional Taman Nasional Karimunjawa. Journal of Fisheries Resources Utilization Management and Technology, Vol. 1 (1), Hal. 97 - 107

Badan Pusat Statistik Kabupaten Kepulauan Sangihe. 2019. Kecamatan Manganitu dalam Angka 2019.

Hargiyanto, I. T., Anggawangsa, R. F., \& Wudianto. 2013. Perikanan Pancing Ulur di Palabuhanratu: Kinerja Teknis Alat Tangkap. Jurnal Lit. Perikanan Indonesia, Vol. 19 (3), Hal. 121 130

Hariyanti, E., Werdiningsih, I., \& Surendro, K. 2011. Model Pengembangan Dashboard untuk Monitoring dan Evaluasi Kinerja Perguruan Tinggi. JUTI: Jurnal Ilmiah Teknologi Informasi, Vol. 9 (1), Hal. 13 - 20

Jumsurizal, Nelwan A., \& Kurnia, M. 2014. Produktivitas Penangkapan Ikan Tenggiri (Scomberomorus commerson) Menggunakan Pancing Ulur di Perairan Kabupaten Bintan. Jurnal IPTEKS PSP, Vol. 1 (2), Hal. 165 - 173

Kristiawan, H. A., Boesono, H., \& F., A. D. P. 2013. Perbedaan Penggunaan Mata Pancing dan Jaket
Tuna Terhadap Kecepatan Penarikan Hasil Tangkapan Tuna (Thunnus albacores) dengan Alat Tangkap Pancing Ulur di Perairan Sukabumi, Jawa Barat. Journal of Fisheries Resources Utilization Management and Technology, Vol. 2 (1), Hal. $104-113$

Kusnadi. 2008. Akar Kemiskinan Nelayan. LkiS: Yogyakarta

Manoppo, L. 2014. Optimalisasi Pengelolaan Sumber Daya Ikan Selar (Selaroides leptolepis) Melalui Penguatan Kearifan Lokal Melombo di Desa Salurang Kabupaten Kepulauan Sangihe. Disertasi. Program Doktor Ilmu - ilmu Pertanin Minat Pengelolaan Sumberdaya Alam dan Lingkungan Program Pascasarjana Fakultas Pertanian Universitas Brawijaya: Malang

Pratama, D. S., Gumilar, I., \& Maulina, I. 2012. Analisis Pendapatan Nelayan Tradisional Pancing Ulur di Kecamatan Manggar, Kabupaten Belitung Timur. Jurnal Perikanan dan Kelautan, Vol. 3 (3), Hal. 107 - 116

Rahmat, E. Penggunaan Pancing Ulur (Hand line) untuk Menangkap Ikan Pelagis Besar di Perairan Bacan, Halmahera Selatan. BTL, Vol. 6 No. 1, Hal. $29-33$

Sadiyah, K., Nurita, E., \& Lesmana, R. 2019. Pelatihan Manajemen Keuangan bagi Nelayan Kepulauan Seribu Pasca Penjualan Hasil Tangkapan Ikan. Jurnal Abdimas, Vol. 1 (1), Hal. 1 - 7

Sarapil, C. I. \& Kumaseh, E. I. 2019. Modifikasi Alat Tangkap Bubu Lokal untuk Meningkatkan Pendapatan Kelompok Nelayan di Pulau Beeng Laut Kabupaten Kepulauan Sangihe. Jurnal Ilmiah Tatengkorang, Vol. 1 (0)

Sarapil, C. I., \& Wuaten, J. F. 2017. Manajemen Rumah Tangga Nelayan Penangkap Ikan Tuna (Thunnus albacores) Studi Kasus di Pesisir Pantai Akembuala Kelurahan Santiago Kecamatan Tahuna Kabupaten Kepulauan Sangihe. Jurnal Ilmiah Tindalung, Vol. 3 (1), Hal. $23-30$ 
48 Jurnal Ilmiah Tatengkorang, Volume 4, Nomor 2, November 2020, hlm. 43-48

Sipahelut, M., Wiryawan, B. \& Nurani, T. W. 2010. Analisis Pemberdayaan Masyarakat Nelayan di Kecamatan Tobelo Kabupaten Halmahera Utara. Tesis. Program Magister Sains Mayor Sistem dan Pemodelan Perikanan Tangkap, Sekolah Pascasarjana IPB, Bogor

Surahman, A. \& Ilhamdi, H. 2018. Karakteristik dan Hasil Tangkapan Pancing Ulur di Perairan
Teluk Cendrawasih Samudera Pasifik. Buletin Teknik Litkayasa Sumber Daya dan Penangkapan, Vol. 16 (2), Hal. 83 - 86

Tamarol, J. \& Sarapil, C. I. 2018. Kajian Sosial Ekonomi Rumah Tangga Nelayan Pancing Ulur (Hand line) Perorangan di Kecamatan Tabukan Utara Kabupaten Sangihe. Jurnal Ilmiah Tindalung, 4(2): $89-98$ 